\section{Burgos, B. (coord.) \\ Pensar y hacer en el medio rural. Prácticas culturales en contexto}

Madrid: Ministerio de Cultura y Deporte, 2020

El escenario de crisis que la pandemia de Covid-19 ha dejado en el mundo que conocemos no ha hecho sino anunciar, de manera urgente -aunque temporal-, la necesidad de un cambio de paradigma ante la crisis climática y ecológica que acecha la vida en nuestro planeta. El modelo civilizatorio actual, basado en la idea de un progreso que se sustenta en un crecimiento económico supuestamente infinito, ha dejado atrás todo aquello poco productivo, ineficiente, lento. Y con ello se han extinguido subjetividades, se han perdido historias, modos de vivir y de pensar, y, se han despoblado comarcas enteras. La España vaciada es representativa de este proceso de degradación de lo rural provocado por el urbanocentrismo que caracteriza a la civilización occidental actual. Sin embargo, el parón provocado por la pandemia ha hecho redirigir la mirada al campo y poner en valor aspectos hasta ahora olvidados.

En este contexto nace, tempestivamente, el libro Pensar y hacer en el medio rural. Prácticas culturales en contexto, una obra coral que reflexiona sobre la importancia de crear, mantener y cultivar la cultura en el mundo rural. Cultura entendida como conjunto de saberes, costumbres, sistemas simbólicos e identidad de los pueblos, pero también como herramienta capaz de proporcionar claves para el análisis crítico del contexto y a partir de ello, reformular el relato del mundo rural, su sentido e imaginarios, modificando la percepción social que de este se tiene. Se trata, en suma, de hacer reconverger los caminos bifurcados de los conceptos cultura y cultivar, procedentes de la misma raíz etimológica.

La obra, definida por sus autores como un texto "a medio camino entre el manual, el ensayo y la propuesta metodológica", reúne las aportaciones de quince autores que plantean propuestas, experiencias y herramientas, desde los que superar la dinámica tradicional de programación-consumo para buscar nuevas formas de considerar la cultura como bien común y no como mero servicio. Dirigido a gestores culturales, agentes de desarrollo local y a la sociedad en general, el libro recoge cuestiones prácticas como el proceso de definición, puesta en marcha y ejecución de proyectos, así como apartados dedicados a la comunicación o financiación en el ámbito de la gestión cultural. Pero no por ello deja atrás una sólida argumentación teórica, fundamentada en cuestiones como la teoría decolonial o la soberanía alimentaria. El objetivo, en suma, es fomentar la participación y crear nuevas formas de vivir lo rural. Impulsar imaginarios a través de proyectos culturales creados 
desde y para el lugar en el que se crean. El arraigo al territorio, la ecología, la reivindicación del papel de la mujer en el mundo rural, el aprecio a la diversidad, o el valor de la intergeneracionalidad son elementos clave en la mirada propuesta por estos autores.

La publicación de un libro que apuesta por el mundo rural en un momento como el que estamos viviendo, tiene un valor añadido si el ente que lo promueve y financia es el público. Pensar y hacer en el mundo rural surge en el marco del programa de Cultura y ciudadanía, nacido en 2015 dentro de la Dirección General de Industrias Culturales, Propiedad Intelectual y Cooperación del Ministerio de Cultura y Deporte, con el objetivo de abrir un espacio de diálogo, investigación e intercambios en torno a las políticas culturales de nuestro país. El libro supone, pues, un avance en las políticas de desarrollo de la España rural a través de la creación de espacios de encuentro que permitan reconstruir nuestra relación con la naturaleza y con todo un patrimonio social y cultural que ha de protegerse y fomentarse.

Laura Cabezas Vega | Dpto. de Historia Contemporánea, Universidad de Granada

URL de la contribución <www.iaph.es/revistaph/index.php/revistaph/article/view/4782> 